\title{
Comparison of total phenols, flavonoids and antioxidant activity of various crude extracts of Hyoscyamus gallagheri traditionally used for the treatment of epilepsy
}

\author{
Mohammad Amzad Hossain*, Afaf Mohammed Weli and Sitti Hadidja Ibrahim Ahmed
}

\begin{abstract}
Background: Most of the locally available medicinal plant is used as medicine through different ways since the ancient time. Hyoscyamus gallagheri (H. gallagheri) is one of the rare medicinal plant which is indigenous to Oman as well as Gulf countries. The main target of this study is to estimate the total phenols and flavonoids content and evaluate the antioxidant activities of the aerial parts extracts which were collected from the southern part of Oman.

Methods: Initially, the powder of aerial parts of the selected plant was extracted with a polar solvent. The prepare extract was the successive fractionation by different polarities of solvents. All the extracts were used for the estimation of total phenols and flavonoids content by common Folin-Ciocalteu reagent (FCR) and calorimetric methods. In addition, the extracts were evaluated for their antioxidant activity by spectroscopic technique through a,a-diphenyl-picrylhadrazyl (DPPH) method.

Results: In the present experiment, the ethyl acetate extract contains the highest amount of phenols and the lowest in hexane extract. However, the highest amount of flavonoids was obtained from butanol extracts and the lowest in water aerial extract. In addition, the highest antioxidant activity showed in the ethyl acetate aerial extract and the lowest was in the hexane aerial extract. The other aerial extracts also showed the similar antioxidant activity comparable to Gallic acid standard.
\end{abstract}

Conclusion: It was also observed that there is a significant correlation between the antioxidant and total phenols. Therefore, the best activity aerial extract might be used for the treatment of human diseases in near future.

Keywords: Hyoscyamus gallagheri, Rare medicinal plant, Phenol, flavonoids, Antioxidant activity

\section{Introduction}

The search of relief from illness, through application of medicinally active plant crude drugs, has its origins in the distant pre-historic past. Egyptian medicine was flourishing several thousand years ago. The oldest records showed that the medicinal plant used as tablets was discovered in Mesopotamia and documented the ways of using hundreds of plant species. Still, now most of them are used to treat the human diseases [1].

\footnotetext{
* Correspondence: amzad@unizwa.edu.om

School of Pharmacy, College of Pharmacy and Nursing, University of Nizwa, P. O. Box 33, Postal Code, 616 Nizwa, Sultanate of Oman
}

Plant medicines are significant source of pharmaceuticals through several ways, which includes i) pure active compounds in their native form that are difficult or expensive compare to synthesize one, ii) as active compounds which have been modified to reduce toxicity and improve efficacy, iii) as models for development of synthetic analogs with similar biological activities, and iv) as inactive or poorly-active, but novel, chemical skeletons which promise interesting discoveries through modification [2, 3]. In addition, it is to contribute to pharmaceutical development, however, studies of the biological activity and chemistry of traditionally-used medicinal crude drugs should contribute to the rationalized use 
of these plants by the human population that depends on them for daily, front-line health care $[4,5]$.

Another vital role played by natural products as therapeutic materials is in the herbal industry in the U.S., as well as in European therapeutics markets where herbal drugs are sold and prescribed as standardized medicines. Pharmacognosy is one of the disciplines that have most actively embraced the development and promotion of naturally derived therapeutic materials, and has been successfully applying modem techniques to the discovery, re-discovery, development and standardization of marketable therapeutics [4-6]. It has been noted that nearly $50 \%$ of United States prescriptions filled in 1967 include in the formulation a natural drug product component derived from either higher plant, microbial, animal or mineral sources; a prescription audit in 1991 reported similar results [7].

Hyoscyamus gallagheri (H. gallagheri) is a rare medicinal plant, indigenous to Oman as well as some Gulf countries, which belongs to the family of Solanaceae $[8,9]$. It is a flowering perennial herb with woody stems (Fig. 1). The stem length is about $1 \mathrm{~m}$ with gray-green. The leaves are crowded start from the branches. The size of the leaves is $50-70 \times 10-15 \mathrm{~mm}$ with fleshy and oval size and the flowers are yellow with purple marking. The flowering starts during the September. The fruits are brown and papery with capsule size. The chemistry of the studied plants (H. gallagheri) has not been studied yet. However, the other species and genus of this family were well studied and found to exhibit broad spectrum biological activities and also several antimicrobial and cytotoxic principles were isolated and characterized from the other species which belong to this family $[10,11]$. Traditionally, the selected plant species are used in Oman for treatment of insanity, epilepsy, toothache, hypertension, snake and scorpion bites [9, 12]. The extract or juice of leaves is used as a hair tonic for promoting hair growth $[11,12]$. In this context, the present study is undertaken to estimate the amount of phenols and flavonoids contents and antioxidant activity of the aerial parts of different polarities extracts of $H$. gallagheri.

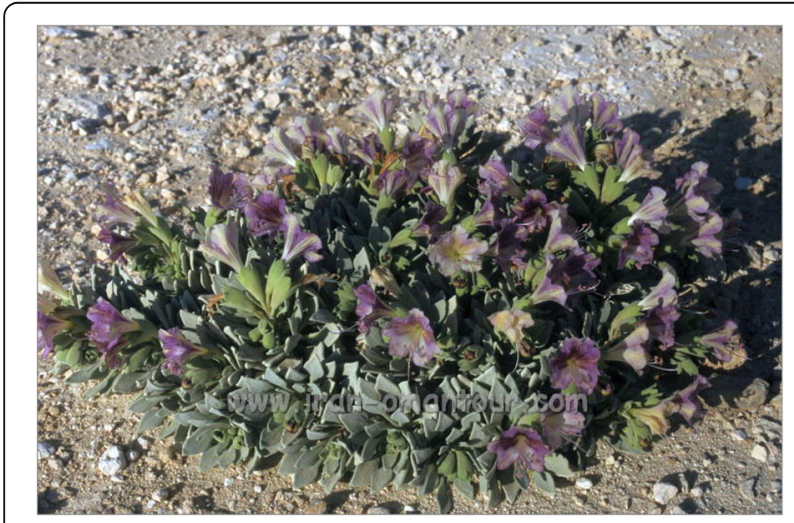

Fig. 1 Plant picture

\section{Materials and methods}

Chemicals, $\alpha, \alpha$-diphenyl-picrylhadrazyl (DPPH), gallic acid, Folin-Ciocalteu reagent (FCR) were bought from E. Merck (Germany). The solvents used for extraction were methanol, hexane, butanol, chloroform, dimethyl sulphoxide (DMSO), $\mathrm{NaNO}_{3}, \mathrm{NaOH}$, and other general chemical and solvents were bought from Sigma-Aldrich Company Limited. The remaining other chemicals used in this experiment were of analytical grade.

\section{Plant sample}

The aerial parts of $H$. gallagheri were collected in the month of September, 2018 from Dhofar and the collected plant was authenticated by local area people and Associate Professor Dr. Syed Abdullah Gilani at the Department of Biological Sciences, University of Nizwa, Nizwa, Sultanate of Oman. The samples were transported to the Laboratory, Nizwa University for further process.

\section{Preparation of samples}

The $H$. gallagheri aerial parts samples were washed to remove dust and foreign materials and then air dried at room temperature $\left(25^{\circ} \mathrm{C}\right)$ for 7 days. The dried aerial parts of the plant $(100 \mathrm{~g})$ were pulverized into coarse powder (approximately $2 \mathrm{~mm}$ mesh) by using a blender. The coarse powder samples were kept in a safe place to avoid contamination.

\section{Extraction procedure}

To prepare extract, Soxhlet extraction method was used for the powder samples of $H$. gallagheri $(100 \mathrm{~g})$ with methanol $(1 \mathrm{~L})$ at $40^{\circ} \mathrm{C}$ over a period of time several days. The solvent was concentrated in vacuo at reduced pressure and temperature $\left(40^{\circ} \mathrm{C}\right)$ to obtain the corresponding extracts $(9.7 \mathrm{~g})$. The dried extract $(7 \mathrm{~g})$ was dissolved in water $(200 \mathrm{ml})$ by using sonication and prepared different fraction by different polarities of solvent starting from nonpolar solvent through successive fractionation [13]. All separated fractions were evaporated at reduced pressure and temperature $\left(40^{\circ} \mathrm{C}\right)$ to obtain the corresponding extracts (hexane $(1.09 \mathrm{~g})$, chloroform $(1.99 \mathrm{~g})$, ethyl acetate $(2.17 \mathrm{~g})$ and butanol $(0.839 \mathrm{~g})$. The rest water part also evaporated by the same way and it is considered as a water extract $(0.43 \mathrm{~g})$. All polarities dry extracts including methanol extract (total six) were used for the determination of phenols, flavonoids and antioxidant activity using the selected standard protocols.

\section{Total phenolic content (TPC) determination}

Established FCR method with minor modification was used for the estimation of the phenol content of the aerial parts six extracts of $H$. gallagheri using gallic acid as an internal standard reported by Al-Saeedi et al. [14]. Five milligrams $(5 \mathrm{mg})$ each fraction extract was dissolved in methanol in a 
$5 \mathrm{ml}$ of volumetric flask. $10 \% \mathrm{FCR}$ and $6 \% \mathrm{Na}_{2} \mathrm{CO}_{3}$ were prepared by the addition of water in a $50 \mathrm{ml}$ of volumetric flask. At first, three hundred microliters of each extract was taken in a $10 \mathrm{ml}$ of glass test tube and instantly added 1.5 $\mathrm{ml}$ of $10 \%$ FCR solution. Then all the glass test tubes containing mixture were shaken and left for $5 \mathrm{~min}$ and added $1.5 \mathrm{ml}$ of $6 \% \mathrm{Na}_{2} \mathrm{CO}_{3}$ solution. All the experimental glass tubes were incubated in a dark place for $2 \mathrm{~h}$ at room temperature. Simultaneously, the gallic acid standard at various concentrations $(200,100,50$, and $25 \mu \mathrm{g} / \mathrm{ml})$ were prepared in the established protocol as described in extracts. Later on, all plant aerial extracts and gallic acid standard solutions were measured absorbance against the blank as methanol at $760 \mathrm{~nm}$ with a UV/Visible spectrophotometer (UV-1800, Shimadzu, Japan). The phenol content of all different extracts was estimated by using the gallic acid standard calibration curve and the obtained results of total phenols were expressed as microgram of gallic acid equivalent (GAE) per $1 \mathrm{~g}$ of dry extract. All the measurement for the determination of phenol content of each extract was carried out in triplicate.

\section{Determination of total flavonoid content (TFC)}

Established modified $\mathrm{AlCl}_{3}$ calorimetric method was used in this present experiment to estimate the flavonoid content in the aerial parts of six different extracts of $\mathrm{H}$. gallagheri as previously reported by our group [14]. Four milligrams of each extract were dissolved in $4 \mathrm{ml}$ of methanol in a $5 \mathrm{ml}$ of volumetric flask. $5 \% \mathrm{NaNO}_{3}, 5 \%$ $\mathrm{NaOH}$ and $7 \% \mathrm{AlCl}_{3}$ solution were prepared by using water in a $25 \mathrm{ml}$ of volumetric flask. First of all, three hundred microliters of each extract were taken in a sealed glass vial and added $75 \mu \mathrm{l}$ of $5 \% \mathrm{NaNO}_{3}$ and left for $5 \mathrm{~min}$ at room temperature. Later on $1.25 \mathrm{ml}$ of $\mathrm{AlCl}_{3}$ and $0.5 \mathrm{ml}$ $\mathrm{NaOH}$ were added to each vial. Then it was sonicated and incubated for $5 \mathrm{~min}$ at room temperature. Simultaneously, the quercetin standard at different concentrations (200, 100,50 , and $25 \mu \mathrm{g} / \mathrm{ml}$ ) were prepared in the same protocol as described in extracts. After incubation, the absorbance of all working solution and standard solution was measured against methanol blank at $510 \mathrm{~nm}$. The flavonoids content of all different extracts was estimated by using the quercetin standard calibration curve and the obtained results of flavonoids were expressed as microgram of quercetin equivalent $(\mathrm{Qu})$ per $1 \mathrm{~g}$ of dry extract. All the measurement for the determination of flavonoids content in the extract was carried out in triplicate.

\section{Evaluation of antioxidant activity}

The antioxidant activity of the aerial extract of $H$. gallagheri was assessed according to method describe by Alabri et al. [15], with further modifications. In this experiment, the DPPH reagent was used as the source of producing free radicals. The absorbance of free radicals of all aerial extracts at various prepared concentrations was measured at 520 $\mathrm{nm}$ to decolorize upon their reduction ability. In the current study, as a standard, antioxidant compound gallic acid was used. Different concentrations of each extract (400, 200, 100, 50, and $25 \mu \mathrm{g} / \mathrm{ml}$ ) were formed according to dilution method. At first, three hundred microliters (300 $\mu \mathrm{l})$ of each concentration of each polarity extract were placed in a $5 \mathrm{ml}$ of the glass tube and added $1.2 \mathrm{ml}$ DMSO solution. Then $2.7 \mathrm{ml}$ of DPPH (3.3 mg in $100 \mathrm{ml}$ of DMSO) reagent was poured into the glass tube. All them were mixed together and held in the dark for $1.5 \mathrm{~h}$. The decolourization of the DPPH was measured as absorbance at $516 \mathrm{~nm}$ using a UV-Vis spectrophotometer. In this experiment, DPPH solvent is being used as blank. The antioxidant activity was calculated of each concentration extract through the percentage of inhibition by using the formula

$$
\text { \%Inhibition }=\text { Ao-As } / \text { Ao } * 100
$$

Where Ao is the Absorbance of control and As is the absorbance of the test sample.

\section{Data analysis}

The collected data in this experiment are expressed as means \pm standard deviation (SD). The experimental data were statistically analysed and the significance of differences between samples was determined by SPSS version 10.0 software. Values of $p<0.05$ were considered statistically significant.

\section{Results}

\section{Plant extracts}

The collected plant aerial parts were processed and extracted with methanol solvent. The methanol solvent was removed from the extract and dissolved in water and successively fractioned with various solvents starting from nonpolar solvent. The mass of various polarities extracts from the aerial parts of $H$. gallagheri is presented in Table 1. In this experiment, the methanol extract through the Soxhlet extractor and its derived fraction are presented in Table 1. The yield of methanol extract obtained from the aerial parts was $9.7 \%$. After

Table 1 Yield of various polarities extracts from the aerial parts of H. gallagheri

\begin{tabular}{ll}
\hline Extract & $\begin{array}{l}\text { Yield } \\
(\mathrm{gm})\end{array}$ \\
\hline Methanol & 9.7 \\
Hexane & 1.09 \\
Chloroform & 1.99 \\
Ethyl acetate & 2.17 \\
Butanol & 0.83 \\
Water & 0.43 \\
\hline
\end{tabular}


fractioned, the highest yield was obtained in ethyl acetate and the lowest in the water.

\section{Total phenol content}

Total phenol contents of various polarities extracts obtained from the aerial parts of $H$. gallagheri were estimated modified FCR method describe by Al-Saeedi et al. [14]. In this assay, the FCR phenol detected reagent reacts with phenolic compounds under basic conditions to form chromogens that can be detected at $750 \mathrm{~nm}$. The total phenol content of six plant extracts ranges from 45.58$1000 \mu \mathrm{g}$ GAE/1 g dry extract (Fig. 2). Among the six aerial various polarities extracts, the maximum amount of total phenols found in ethyl acetate and minimum amount was in hexane extract. The experimental results obtained from the various extracts are presented in Table 2.

\section{Total flavonoids content}

Established modified calorimetric method was used for the estimation the flavonoid contents of the aerial of six different extracts of $H$. gallagheri as previously reported by our group [14]. In this method, the applied flavonoids reagent reacts with desire flavonoids compounds under the applied conditions to form flavonoids complex that can be detected at $510 \mathrm{~nm}$. The range of flavonoids contents of six plant extracts from 1.86-185.17 $\mu \mathrm{g}$ QU/1 g dry extract (Fig. 3). Among the six aerial various polarities extracts, the significant amount of total flavonoids found in butanol and the minimum amount was in the ethyl acetate extract. The experimental results obtained from the various extracts are presented in Table 3.
Table 2 Total phenol contents of various extracts of H. gallagheri

\begin{tabular}{lll}
\hline Extract & Absorbance & $\begin{array}{l}\text { Total phenol } \mu \mathrm{g} \\
\text { GAE/1 g dry extract }\end{array}$ \\
\hline Hexane & 0.251 & $45.58 \pm 0.29$ \\
Ethyl acetate & 0.381 & $1000 \pm 0.10$ \\
Chloroform & 0.316 & $523.50 \pm 0.62$ \\
Methanol & 0.348 & $758.5 \pm 0.11$ \\
Butanol & 0.327 & $604 \pm 0.23$ \\
Water & 0.352 & $785 \pm 0.46$
\end{tabular}

Triplicate experiment

\section{Evaluation of antioxidant activity}

The antioxidant activity was measured according to the method developed by Alabri et al. [15], with further slight modifications. Almost all the crude extract showed the significant percentage of inhibition comparable to gallic acid. Among them, the highest inhibition was obtained ethyl acetate and the lowest was in hexane extract. The antioxidant as a percentage of inhibition is presented in Table 4 and Fig. 4.

\section{Discussion}

Native communities in the Sultanate of Oman utilize a plenty of indigenous medicinal plants since the ancient times as a primary health care. However, there are no proper herbalist documentation or biological studies on the indigenous plants existed in current literature.

More than three-quarters of the active constitutes which are derived from plants presently available in global use to treat human diseases that have been partially discovered through established research steps on folk and ethnomedicinal uses. It is authoritative that ethno

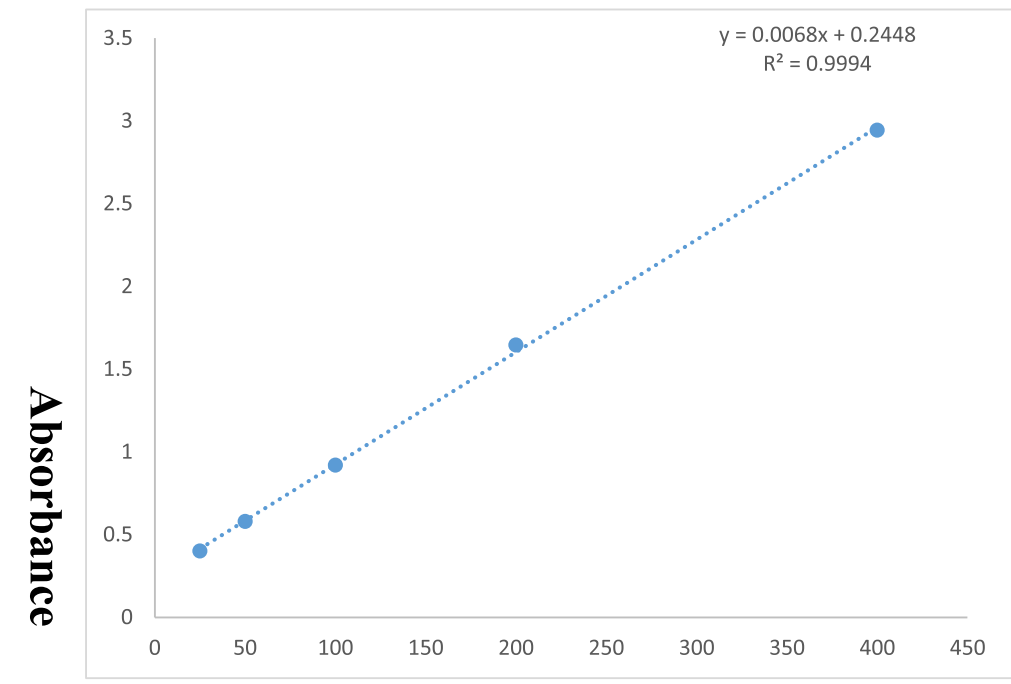

Conc. (ppm)

Fig. 2 Standard curve of gallic acid 


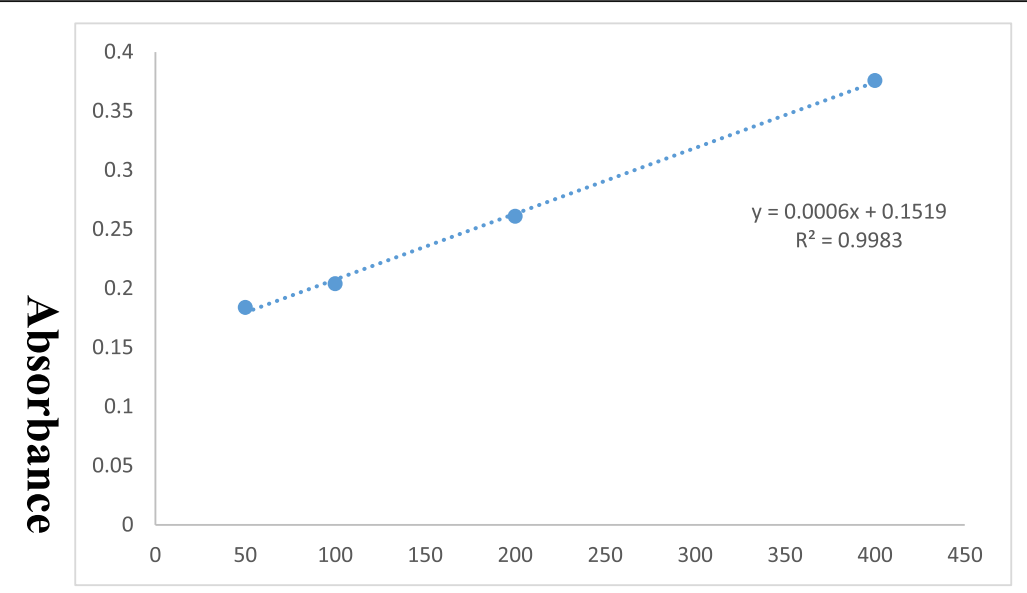

Conc. ppm

Fig. 3 Calibration curve for Quercetin standard

botanically based research to find active phytochemicals be inaugurated on a broad scale production [16].

This above data encouraged us to exploit the available natural resources in Oman towards the study on pharmacological and alleviation of different human oxidative stress. All kinds of oxidative stress plays a major part in the pathogenesis of numerous main human chronic diseases, such as cancer, heart diseases, diabetes and Alzheimer's condition. Also, transferable sicknesses are a vital concern in our present society due to the advent of manifold drug resistant strains of bacteria that cause millions of deaths worldwide. Therefore, the selected medicinal plant was undertaken to screen the bioactivities and phenols and flavonoids contents which were collected from the Southern part of Oman. The plant aerial parts were collected during the month of September, 2018. After collection, the samples necessary process was done in the preparation of the extract. Total of six extracts with increasing polarity were prepared according to the standard protocols mentioned above in the experimental sections.

Table 3 Total flavonoids content of various extracts of $H$. gallagheri

\begin{tabular}{lll}
\hline Extract & Absorbance & $\begin{array}{l}\text { Total flavonoid } \mu g \\
\text { QU/gm dry skin }\end{array}$ \\
\hline Hexane & 0.388 & $23.25 \pm 0.11$ \\
Ethyl acetate & 0.357 & $4.04 \pm 0.23$ \\
Chloroform & 0.456 & $29.30 \pm 0.09$ \\
Methanol & 0.356 & $20.44 \pm 0.26$ \\
Butanol & 0.49 & $185.17 \pm 0.49$ \\
Water & 0.336 & $1.86 \pm 0.18$ \\
\hline
\end{tabular}

All data triplicate measurement
Medicinal plants are a gift of Allah and they contain a several groups of biologically active constituents, minerals, different types of vitamins and minor percentage of trace elements which is badly needed for human health. All the chemical constituents are a fascinating yet secretive group of several thousands of phytochemicals found in plant sources. Most of the phytochemicals are well known to be biologically active, which may exert a beneficial action on the human body. The mentioned phytochemicals have a wide range of positive action on the human body which include mainly the complex carbohydrates, flavonoids, terpenoids, proteins, several organic acids, alcohols and their corresponding complex, oils, tannins, saponins glycoside, glucosides and so on [17]. In addition, the primary and secondary compounds produced by plants to support their existence and biological effects. These above mentioned phytochemicals are being researched for nutrition and herbal medicine [18]. They have significant antioxidants, antimicrobial, antiviral and inspiration hormones, immune function, various inflammations, detoxification and other cell functions. Most of the natural sources, especially plant sources afford a source of biologically active compounds which are currently used as poisons, drugs or beneficial agents [19].

\section{Total phenol content}

The total phenols content assay of the aerial six extracts was performed according to a procedure established by Al-Saeedi et al. [14]. All extracts exhibit some amount of total phenol content. The maximum level of phenols was obtained in the ethyl acetate extract and minimum was in hexane extract and the following hierarchy: ethyl acetate $>$ water $>$ methanol $>$ chloroform $>$ butanol $>$ hexane 
Table 4 Antioxidant activity results of various polarities extracts of H. Gallagheri

\begin{tabular}{|c|c|c|c|}
\hline Extract & $\begin{array}{l}\text { Concentration } \\
(\mathrm{ppm})\end{array}$ & $\begin{array}{l}\text { Absorbance } \\
(\mathrm{nm})\end{array}$ & $\%$ Inhibition \\
\hline \multirow[t]{5}{*}{ Hexane } & 400 & 0.039 & $96.43 \pm 0.09$ \\
\hline & 200 & 0.13 & $96.40 \pm 0.21$ \\
\hline & 100 & 0.168 & $84.60 \pm 0.42$ \\
\hline & 50 & 0.182 & $83.30 \pm 1.08$ \\
\hline & 25 & 0.095 & $91.30 \pm 0.36$ \\
\hline \multirow[t]{5}{*}{ Chloroform } & 400 & 0.029 & $97.30 \pm 0.12$ \\
\hline & 200 & 0.074 & $93.20 \pm 0.30$ \\
\hline & 100 & 0.132 & $55.50 \pm 0.55$ \\
\hline & 50 & 0.153 & $86.00 \pm 0.51$ \\
\hline & 25 & 0.121 & $88.90 \pm 0.69$ \\
\hline \multirow[t]{5}{*}{ Ethyl acetate } & 400 & 0.021 & $98.07 \pm 0.71$ \\
\hline & 200 & 0.024 & $97.80 \pm 0.08$ \\
\hline & 100 & 0.094 & $91.30 \pm 0.19$ \\
\hline & 50 & 0.129 & $88.10 \pm 0.17$ \\
\hline & 25 & 0.096 & $91.20 \pm 0.76$ \\
\hline \multirow[t]{5}{*}{ Butanol } & 400 & 0.018 & $51.30 \pm 0.12$ \\
\hline & 200 & 0.532 & $98.60 \pm 0.43$ \\
\hline & 100 & 0.015 & $97.00 \pm 0.14$ \\
\hline & 50 & 0.022 & $97.40 \pm 0.22$ \\
\hline & 25 & 0.032 & $97.07 \pm 0.32$ \\
\hline \multirow[t]{6}{*}{ Water } & 400 & 0.028 & $97.07 \pm 0.76$ \\
\hline & 200 & 0.135 & $87.60 \pm 0.33$ \\
\hline & 100 & 0.470 & $56.90 \pm 0.15$ \\
\hline & 50 & 0.286 & $73.80 \pm 0.13$ \\
\hline & 25 & 0.212 & $89.02 \pm 0.10$ \\
\hline & 400 & 0.037 & $98.13 \pm 0.15$ \\
\hline \multirow[t]{4}{*}{ Gallic acid } & 200 & 0.038 & $98.09 \pm 0.71$ \\
\hline & 100 & 0.038 & $97.80 \pm 0.34$ \\
\hline & 50 & 0.039 & $97.50 \pm 0.19$ \\
\hline & 25 & 0.040 & $97.01 \pm 0.21$ \\
\hline
\end{tabular}

All experiment triplicates

extract (Table 2). The present phenols content results are unable to compare with other results due to the usability of the literature on the selected plant species. But, there are several reports are available in the literature on the other species belong to this family. The total phenol content of other species also showed the average amount present in the plant extracts reported [20, 21].

\section{Total flavonoids content}

Similarly, total flavonoids content of the aerial six extracts of $H$. gallagheri was performed according to the procedure established by Al-Saeedi et al. [14]. All extracts showed some amount of total flavonoids content. In our experiment, butanol extract has a significant amount of flavonoids compare to other prepared extract. But the minimum amount of flavonoids was obtained in water extract and the following hierarchy: butanol>chloroform $>-$ hexane $>$ methanol $>$ ethyl acetate $>$ water extract (Table 3 ). This result showed that most of the flavonoids were present in the butanol aerial extract. In addition, butanol is polar solvent and all of the flavonoids obtained in the butanol extract are polar in nature. The flavonoids content results are unable to compare with other results due to the usability of the literature on the selected plant species. But, several reports are available in literature on the other species belong to this family. Several authors reported on the other species belonging to the family and it was supported in our results $[22,23]$.

\section{Evaluation of antioxidant activity}

The determination of antioxidant activity of aerial various extracts of $H$. gallagheri was measured by the DPPH method developed by Alabri et al. [15], with further slight modifications. Almost all the crude extracts showed significant inhibition compared to gallic acid. Among them, the highest inhibition was obtained in ethyl acetate and the lowest was in hexane extract. The antioxidant as a percentage of inhibition is presented in Table 4 and Fig. 4. All crude extract basically reacts with $\mathrm{DPPH}$ and form a free radical and finally gradually decrease the colour of DPPH. The present experiment, all the aerial extracts from $H$. gallagheri were able to decolourize the DPPH colour. However, the ethyl acetate gave us the best results for decolourization that indicates the extract contains the maximum number of antioxidant compounds which can decolorize the colour rapidly of DPPH. We could not find any reports on antioxidant activity of the various polarities extracts of the selected plant species, however, there are several reports available on antioxidant activity screening belongs to this family's plant species [24-28]. Therefore, we are unable to compare our results to the other reports. However, our experimental data are consistent with the other species belonging to this family.

\section{Conclusion}

In our experimental, data showed that all the crude extracts from the aerial parts of $H$. gallagheri has a significant amount of total phenols and flavonoids contents through the methods of FCR and calorimetric methods. Among the prepared extracts, ethyl acetate contains the maximum total phenol content. Similarly, the butanol extract contains the maximum amount of flavonoids content. In addition, the antioxidant activity of the six prepared extracts showed also the good inhibition 


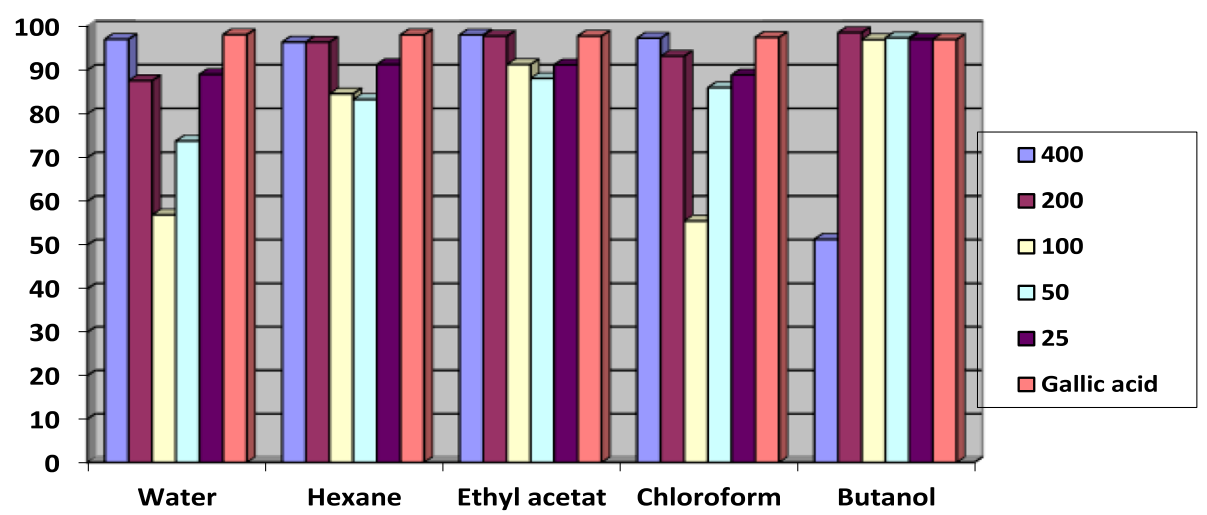

Fig. 4 Antioxidant capacity of different crude extracts from aerial samples of $H$. gallagheri

against the DPPH. The ethyl acetate extract showed the maximum activity among the various extracts. Our results also showed that there are very good correlation with the total phenol and antioxidant activity. Therefore, we might consider the highest activity extract as a natural antioxidant for the protection of different curable and incurable diseases.

\section{Abbreviation}

DMSO: Dimethyl sulphoxide; DPPH: a,a-diphenyl-picrylhadrazyl; FCR: FolinCiocalteu reagent; $\mathrm{Na}_{2} \mathrm{SO}_{4}$ : Sodium sulphate; $\mathrm{NaNO}_{3}$ : Sodium nitrate; $\mathrm{NaOH}$ : Sodium hydroxide

\section{Acknowledgements}

One of our authors is grateful to the student support fund, University of Nizwa for financial support. We are also grateful to the University of Nizwa for necessary chemicals and laboratory support. Thanks to Nadia Banioraba, Lab Assistant for her continuous help and assist to perform our experiment.

\section{Funding}

This research study was not granted any specific fund.

\section{Availability of data and materials}

Not applicable.

\section{Authors' contributions}

MAH prepared and submitted the manuscript. AMW reviewed and gave critical analysis of the manuscript. KS contributed to the work. Both authors read and approved the final manuscript.

\section{Ethics approval \\ Not applicable.}

\section{Consent for publication}

Not applicable.

\section{Competing interests}

The authors declare that they have no competing interests.

\section{Publisher's Note}

Springer Nature remains neutral with regard to jurisdictional claims in published maps and institutional affiliations.

Received: 5 March 2019 Accepted: 12 May 2019

Published online: 20 May 2019

\section{References}

1. Newman DJ, Cragg GM, Snader KM. The influence of natural products upon drug discovery. Nat Prod Rep. 2000;17:215-34.
2. Harvey A. Strategies for discovering drugs from previously unexplored natural products. Drug Disc Today. 2000:5:294-300.

3. Strohl WR. The role of natural products in a modem drug discovery program. Drug Disc Today. 2000:5:39-41.

4. Heinrich M. Ethnobotany and its role in drug development. Phytother Res. 2000;14:279-488.

5. Sampson JH, Phillipson JD, Bowery NG, O'Neill MJ, Houston JG, Lewis JA. Ethnomedically selected plants as sources of potential analgesic compoimds: indication of in vitro biological activity in receptor binding assays. Phytother Res. 2000;14:4-29.

6. Cragg GM, Newman DJ, Snader KM. Natural products in drug discovery and development. J Nat Prod. 1997;60:52-60.

7. Robbers JE, Speedie MK, Tyler VE. Pharmacognosy and Pharmacobiotechnology. Baltimore, MD: Williams and Wilkins Publishers; 1996.

8. Miller AG, Morris M. Plants of Dhofar (The southern region of Oman; traditional, economic and medicinal uses). The office of the Adviser for Conservation of the Environment, Diwan of Royal Court, Sultanate of Oman, 1988; pp. 361.

9. Pat P, Karol S. Treatment of Cancer sixth edition, vol. 1: CRC Press; 2014. p. 873.

10. Tandon C, Mathur P, Sen M. Antimicrobial compounds in different species of Datura. Afr J Microbiol Res. 2014;8(21):2090-8.

11. Loutfy B. Kew Bull. 1991;46(2):297-9.

12. Ghazanfar SA. Handbook of Arabian medicinal plants. CRC press, Boca Raton. USA: Florida; 1991.

13. Al-Amri FS, Hossain MA. Comparison of total phenols, flavonoids and antioxidant potential of local and imported ripe bananas. Egypt J Basic Appl Sci. 2018;5:245-51.

14. Al-Saeedi AH, Al- Ghafri MTH, Hossain MA. Comparative evaluation of total phenols, flavonoids content and antioxidant potential of leaves and fruit extracts of Omani Ziziphus jujuba L. Pac Sci Rev A: Nat Sci Eng. 2016;18:78-83.

15. Alabri THA, Al-Musalami AHS, Hossain MA, Weli AM, Al-Riyami Q. Comparative study of phytochemical screening, antioxidant and antimicrobial capacities of fresh and dry leaves crude plant extracts of Datura metel L. J King Suad Uni Sci. 2014:26:237-43.

16. Lewis W, Elvin-Lewis M. Basic, quantitative and experimental research phases of future ethnobotany with reference to the medicinal plants of South America. In- Ethnobotany and the Search for New Drugs (Ciba Foundation Symposium 185) Chadwick, D. J. and Marsh, J. (eds.), 1994. Wiley, Chichester, 1994; 60-72.

17. Zimmerman M. Phytochemicals. Nutrients of the Future (http: // www.fsb. upm.edu.mv/ suhaimi/ nutra.html, accessed 12/12/2002.), 2002.

18. Termentzi A, Zervou M, Kokkalou E. Isolation and structure elucidation of novel phenolic constituents from Sorbus domestica fruits. Food Chem. 2018;116:371-81.

19. Valko M, Rhodes CJ, Moncol M, Izakovic M, Mazur M. Free radicals, metals and antioxidants in oxidative stress-induced cancer. Chem Biol Inter. 2006;160:1-40.

20. Farnsworth NR. The role of ethnopharmacology in drug development. In: Chadwick DJ, Marsh J, editors. Bioactive compounds from plants (Ciba Foundation symposium 154). Chichester: Wiley; 1990. p. 2-21.

21. Okmen B, Sigva HO, Mutlu S, Doganlar S, Yemenicioglu A, Frary A, Antioxidant T. Activity and Total phenolic contents in different Turkish eggplant (solanum Melongena L.) cultivars. Inter J Food Proper. 2009;12(3):616-24. 
22. Jesus F. Exploring the phenolic profile, antioxidant, antidiabetic and antihemolytic potential of Prunus avium vegetal parts. Food Res Int. 2018;34:230-8.

23. Helmja K, Vaher M, Gorbatšova J, Kaljurand M. Characterization of bioactive compounds contained in vegetables of the Solanaceae family by capillary electrophoresis. Proc Estonian Acad Sci Chem. 2007:4:172-86.

24. Yao LH, Jiang YM, Shi J, Tomás-Barberán FA, Datta N, Singanusong R, Chen

SS. Flavonoids in food and their health benefits. Plant Foods Human Nutr. 2018:59:113-22.

25. Burda S, Oleszek W. Antioxidant and antiradical activities of flavonoids. J Agric Food Chem. 2001;49:2774-9.

26. Niki Y, Omata A, Fukuhara Y, Saito Y, Yoshida M. Assessment of radical scavenging capacity and lipid peroxidation inhibiting capacity of antioxidant. J Agric Food Chem. 2008:56:8255-60.

27. Pietta PG. Flavonoids as antioxidant. J Nat Prod. 2008;63:1035-42.

28. Seifried $H E$, Anderson DE, Fischer El, Milner JA. A review of the interaction among dietary antioxidants and reactive oxygen species. J Nutr Biochem. 2007:18:567-79.

\section{Submit your manuscript to a SpringerOpen ${ }^{\circ}$ journal and benefit from:}

- Convenient online submission

- Rigorous peer review

- Open access: articles freely available online

High visibility within the field

- Retaining the copyright to your article

Submit your next manuscript at $\boldsymbol{\wedge}$ springeropen.com 